\title{
ERRATUM
}

Jason J. Corso $\cdot$ Guangqi Ye $\cdot$ Gregory D. Hager

\section{Analysis of composite gestures with a coherent probabilistic graphical model}

Published online: 20 October 2005

(C) Springer-Verlag London Limited 2005

\section{Virtual Reality (2005) 8:242-252}

The publishers apologize that Table 1 of the article entitled "Analysis of composite gestures with a coherent probabilistic graphical model" lacked the content that the author had supplied. The correct version of the Table is shown below:

Table 1 Example images of basic GWords

\begin{tabular}{|c|c|c|c|c|c|c|c|c|c|c|}
\hline GWord & Press & Left & Right & Back & Twist & Grab 1 & Grab 2 & Track & Rotate & Stop \\
\hline Stage 1 & $n$ & n & n & n & I & 口 & ] & F & [ & \\
\hline Stage 2 & & [ & 口 & 口 & D & [ & 口 & $\nabla$ & [ & \\
\hline Stage 3 & & 口 & 口 & [ & ป & m. & a & 1 & ㅁ & \\
\hline
\end{tabular}

The original article can be found at http://dx.doi.org/10.1007/ s10055-005-0157-1

J. J. Corso $(\square) \cdot$ G. Ye · G. D. Hager

Computational Interaction and Robotics Lab,

The Johns Hopkins University, Baltimore,

MD 21218, USA

E-mail: jcorso@cs.jhu.edu 